\title{
Fraternidad anárquica. La inflexión republicana de Marx
}

\author{
Anarchical Brotherhood. Marx’s Republican Inflection
}

EUGENIO MUINELO PAZ*

\begin{abstract}
Resumen: apoyándonos en la rehabilitación por Antoni Domènech del concepto de fraternidad, pretendemos señalar la necesidad de reinterpretar hoy a la luz del mismo el pensamiento político de Marx. Tanto sus escritos de juventud como los de madurez brindan una teoría crítica del Estado y del Derecho que estaría animada por una insobornable inspiración ética. Esta nada tendría que ver con la tan denostada "moralización" de la política. Más bien, en la estela de Levinas, tenderemos a leerla como una an-arquía de lo político que nos obligaría a complementar la tradición histórica del republicanismo.

Palabras clave: capitalismo, dominación, fraternidad, republicanismo, anarquía.
\end{abstract}

\begin{abstract}
: this paper aims to pay attention to the necessity of reinterpreting today Marx's political thought in the light of the political concept of brotherhood, recently rehabilitated by Antoni Domènech. In his early writings, so much as in Capital, Marx offers a critical theory of State and Law, which would be, according to our reading, inspired by an ethical calling. That would have nothing to do with the so called "moralization of politics". On the contrary, as Levinas has shown, it would be question more likely of an an-archy of the political, which will push us to complement the historical tradition of Republicanism.

Key words: capitalism, domination, brotherhood, republicanism, anarchy.
\end{abstract}

\section{La fraternidad preterida ${ }^{1}$}

Desde los eruditos y penetrantes trabajos del malogrado Antoni Domènech no puede caber duda de que la fraternidad fue, de la tan cacareada tríada republicana, el valor más olvidado, el más sometido a un sistemático y deliberado ejercicio de obliteración históricoconceptual. Es, pues, obligado partir de su obra para rescatarlo, reescribir su genealogía y su historia y, sobre todo, redescubrir las potencialidades que aún sigue albergando para pensar e intervenir la política hoy. Como sabemos por su espléndido Eclipse de la fraternidad, el

Recibido: 08/06/2018. Aceptado: 09/07/2018.

* Universidad Complutense de Madrid. Personal Investigador en el departamento de Filosofía y Sociedad. E-mail: emuinelo@ucm.es. Líneas de investigación: filosofía política, filosofía y sociología del derecho, filosofía y sociología de la religión. Publicaciones recientes: "El anarcorrepublicanismo marrano de Karl Marx" en Política Común, vol. 16 (2017) y "El Pablo de Žižek" en Res Publica. Revista de Historia de las Ideas Políticas, vol. 21, $\mathrm{n}^{\circ} 2$ (2018).

1 El presente trabajo se inscribe en mi proyecto de tesis doctoral, hecho posible gracias a un contrato predoctoral UCM-Banco Santander (CT 17/17-CT17/18) en el marco del proyecto de investigación Biblioteca Saavedra Fajardo V (FFI2016-75978-R), financiado por el Ministerio de Economía y Competitividad. 
núcleo vivo de la tradición republicana es la exigencia incondicional de que todo sujeto político se libere el yugo, no sólo de la loi politique de la dominación expresa, sino también, y sobre todo a partir de la emergencia de las sociedades capitalistas, de la loi de famille (travestida de loi civil) que rige tácitamente en el ámbito de la dominación económica.

La perspectiva histórica que nos ofrece Domènech es desde luego de un horizonte amplísimo y de una minuciosidad extrema. Así pues, su exposición completa excede con mucho lo que podamos abordar aquí, si bien no dejaremos de hacernos eco de sus hitos fundamentales. El primero de ellos es para Domènech la insólita elaboración por parte de Efialtes de un programa de democracia plebeya radical en la Atenas del s. V a.C., desmantelado al poco de constituirse, entre otros factores, por la presión oligárquica y por las reticencias aristocráticas de los detentadores del saber, demasiado preocupados como estaban por pergeñar una pulcra e impoluta koinonía politiké incontaminada por la injerencia de los no posidentes (en realidad, del dêmos propiamente dicho) ${ }^{2}$. Al hilo de la Política aristotélica, comenta Domènech que desde ella sólo la virtud o excelencia (areté) otorgaba la aptitud para el mando, y que todo aquel que estuviese a constreñido a vivir del fruto de su trabajo (esto es, carente de eleuthería, de toda actividad autotélica y no puramente instrumental) era por naturaleza incapaz de desarrollar la areté. Lo que de democrático pueda haber en Aristóteles sería, pues, siempre según Domènech, puro pragmatismo: su elaboración, tan preñada de consecuencias en el contexto de la República Romana, de la "constitución mixta" no sería sino una "politeía, una República en la que, sin excluir del todo al pueblo llano, quede asegurado el mando a las clases superiores" (Domènech, 2004, 51); en definitiva, una pátina democrática que disimulase y contuviese los conflictos, la stásis latente de una sociedad atravesada de unos antagonismos tan palmarios como inconciliables. Lo que inquietaba a Aristóteles tras la reforma efiáltica (una de cuyas claves de bóveda era la retribución de fondos públicos para los cargos políticos) era, no tanto que el plebeyo dejase de ser un idiótes ajeno a la vida pública de la pólis, cuanto que pasase a serlo, dedicándose a sus asuntos particulares, el virtuoso desengañado con la intrusión del intrínsecamente perverso dêmos en el ágora.

Asimismo, como apuntábamos, la República Romana experimentó un proceso similar de cierre oligárquico tras la promulgación en el 287 a. C. de la Lex Hortensia, verdadera conquista del ala plebeya frente al poder omnímodo del Senado. Aquí el lugar de Aristóteles lo vendrían a ocupar en el relato de Domènech los anticatilinarios: el optimate Cicerón y Salustio, siempre reacios a la plena integración política de "quien depende civilmente de otro, de $[\ldots]$ quien necesita del permiso de otro para poder vivir y navegar por la vida civil" (Domènech, 2004, 59). De inestimable relevancia para toda la ulterior evolución histórica de Occidente fue en Roma la formación de un dispositivo jurídico formal y abstracto capaz de disciplinar y moldear reticularmente la totalidad del cuerpo social. Se

2 Ha de notarse que es a través de la traducción latina como societas civilis que el término llegará a transmutarse (o quizás no tanto, si secundamos las críticas de Domènech) en la civil society historiada por Ferguson y apologetizada por Adam Smith, también ella una comunidad exclusivamente formada por los posidentes anclados en el "individualismo posesivo" que tanto Hegel como Marx atacaron con su noción de bürgerliche Gesellschaft. Si bien es cierto que estos (sobre todo Hegel) no podían por menos de ver en la koinonía aristotélica algo bien distinto: de hecho, la propia noción hegeliana de Sittlichkeit en la que el bourgeois y el citoyen vendrían a coincidir o integrarse dialécticamente, inspiradora inconfesa de más de una intuición marxiana, se deja derivar de ella sin demasiadas estridencias. 
consideró que las deliberaciones e iniciativas plebeyas obstruían la armonización entre un expansionismo mercantilista cada vez más exacerbado (mayor abundancia de tierras y de mano de obra esclava) y un apego piadoso a las viejas tradiciones romanas del ius civile. Así, el republicanismo ciceroniano plasma una racionalidad aristocrática asentada sobre el presupuesto de la prioridad incuestionable del consensus iuris sobre la multitudo informe vinculada "de cualquier manera", como se dice en De republica, 1, 25, 39: "La república es, por lo tanto, la cosa del pueblo (res populi). Sin embargo, pueblo no es toda unión de hombres congregados de cualquier manera (hominum coetus quoquo modo congregatus), sino la unión de una multitud asociada por el consenso del derecho y la común utilidad (coetus multitudinis iuris consensu et utilitatis communione sociatus)". El tránsito de la mera aglomeración caótica de hombres a una verdadera societas lo posibilita el establecimiento de un repertorio vinculante de normas y sanciones que regulen objetivamente las transacciones privadas de los cives entre sí. No en vano, las nociones más nítidamente definidas y articuladas de todo el derecho privado romano, de largo recorrido histórico, serán las de propiedad y contrato, mediadas por la difusa aequitas formal y simétrica que le era inherente a toda persona que entraba en una relación contractual con cualquier otra. Como es natural, el carente de dominium, de domus, quedaba excluido del juego de las relaciones igualitarias entre los domini (quienes de facto establecen el consensus iuris) y abocado a la inexistencia civil.

No obstante, a pesar de estas distorsiones aristocratizantes Domènech cree poder identificar algo así como un "éthos general de la libertad republicana del mediterráneo clásico", vehiculado a través de la filosofía práctica griega y la jurisprudencia romana, y basado, en el plano de derecho privado, en el "respeto absoluto [...] de la voluntad de los libres" y en la "indivisibilidad" e "inalienabilidad de la personalidad libre", así como, iuspublicísticamente, en la consideración del "Estado" como "una enorme fictio iuris, merced a la cual el aparato administrativo de la República -...- se construía jurídicamente como un individuo libre más de la sociedad civil, completamente despojado de cualquier majestad" (Domènech, 2004, 77). Será en la Asamblea de 1789 donde eclosione verdaderamente el germen de tal éthos de la mano de la autoafirmación revolucionaria del Tercer Estado, si bien, como es sabido, sometido a distintas modulaciones. Dos, fundamentalmente: la del "pueblo llano" (en realidad, como agudamente entrevió Robespierre, un verdadero "Cuarto Estado"), volcado hacia la constitución de una sociedad de (recíprocamente, esto es, fraternalmente) libres e iguales, exenta de todo tipo de dominación vertical; por otro lado, el "pueblo burgués", interesado en la disolución estamental y en la constitución de una sociedad de (formalmente) libres e iguales, dotada de una dominación sedicentemente neutral que impida el acceso material a la libertad e igualdad prometidas.

La consigna robesperriana de la "Fraternidad" aglutinaría en sí misma todo el programa democrático-radical que se opone, según la distinción diseñada por Montesquieu, no sólo a la intromisión de la loi politique en la loi civil, sino sobre todo al mantenimiento de una esfera socialmente invisible gobernada por la loi de famille, y de la que, en última instancia, proceden gran parte de nuestras categorías jurídicas, no siendo la "familia" sino el conjunto de los famuli, de los dependientes del pater familias, del dominus, único sujeto jurídico reconocido por el derecho civil. No es azaroso, pues, que el ideal ilustrado por excelencia haya sido el de la emancipación. ¿Qué significaba, en efecto, la emancipatio sino la transformación del 
hijo de sujeto alieni iuris en sujeto sui iuris? La fraternidad nombraría así una suerte de emancipación universal, de muerte del Padre simbólico que interrumpiría el perpetuo ciclo patriarcal-patrimonial inaugurando el hermanamiento horizontal de todos los dominados.

Domènech dibuja de la siguiente manera los contornos regulativos de esa insistentemente anhelada comunidad de hermanos de horda ya "desprimitivizada", ya hermanos sin Padre:

Pues por lo mismo que «fraternidad» quiere decir universalización de la libertad/ igualdad republicana, quiere decir también: elevación de todas las clases «domésticas» o civilmente subalternas a una sociedad civil de personas plenamente libres e iguales. Lo que implica: allanamiento de todas las barreras de clase derivadas de la división de la vida social en propietarios y desposeídos. Lo que implica: una redistribución tal de la propiedad, que asegure universalmente el «derecho a la existencia» (Domènech, 2004, 87).

Una vez más, el impulso republicano de la Constituyente se vio frustrado por el orden posnapoleónico jurídicamente cristalizado en el Code Civil, que mediante un ensamblaje subrepticio de loi civil y loi de famille logró hacer aparecer al desposeído (quien, en buena lógica, caería bajo la loi de famille) como posidente (como perteneciente, eo ipso, al ámbito de la loi civil): concretamente de esa mercancía tan sui generis, diseccionada genial y perspicazmente por Marx, que es la fuerza de trabajo. Por obra y gracia de esta prodigiosa transustanciación jurídica que es el fetichismo de la mercancía, un contrato entre libres e iguales se torna, en apariencia inexplicablemente (Hic Rhodus, hic salta, como reza la irónica y desafiante admonición que nos lanzaba Marx), en una forma de despotismo irrestricto nada más se traspone el intercambio de equivalentes inicial. La libertad civil, remedo desvaído de la isonomía antigua, se conjuga así con la más crasa subalternidad de quien pasó a llamarse "proletario", nuda fuerza de trabajo y de reproducción social. Y en este punto matiza Domènech incluso las interpretaciones más agudas y lúcidas (Marx y Weber) del trabajo libre asalariado, según él imbuidas de un vestigio de liberalismo metodológico que les habría impedido constatar, más allá de la asimetría material del punto de partida en la negociación del contrato laboral (la cual no pasaría de ser una especie de dominación "implícita"), la violenta dominación estrictamente patriarcal (de ahí, nota pertinentemente Domènech, lo significativo de la metáfora del "patrón") que se ejerce en el interior del proceso productivo mismo ${ }^{3}$.

3 Para hacerle justicia a Marx habría que tener en consideración también ciertos pasajes de su obra de madurez que servirían de contrapunto a una supuesta visión pacífica, desprovista de autoritarismo, de las relaciones laborales en el modo de producción capitalista, la cual tampoco es del todo tan extraíble de sus escritos de juventud como parece querer sugerir Domènech. En cualquier caso, el Marx maduro sostiene con firmeza que lo que supone la dominación en condiciones capitalistas no es su difuminación o atenuación, sino la férrea implementación sistémica y estructural de relaciones de dominación anteriormente dotadas de un carácter "personal" y "concreto", pero que no dejan de ser igualmente despóticas (o, en un sentido jurídico, tal vez incluso más, si se piensa en la centralidad de una figura como la de la conjuratio en el cosmos jurídico medieval y protomoderno) al desprenderse del mismo. Sirvan como ejemplo los dos siguientes fragmentos, tomados de los Grundrisse y de El capital respectivamente: "Hasta tal punto estas relaciones externas [en el sentido de impersonales, abstractas, etc.] no son una remoción de las «relaciones de dependencia», que más bien constituyen únicamente la reducción de éstas a una forma general; son ante todo la elaboración del principio general de las relaciones de 
Contra tal "familiarización" larvada de la sociedad civil, así como contra la reautonomización monárquica del Estado político, se dirigieron furibundamente las Revoluciones de 1848 y ese retoño suyo tardío que será la Comuna de París. Tal contexto de luchas enconadas contra y neutralización progresiva del potencial revolucionario del ideal de la fraternidad democrática ("civilización" tanto de la loi politique, servidumbre supracivil, como de la loi de famille, servidumbre subcivil) será el humus histórico-cultural en el que fermente la reconstrucción socialista de la tradición republicana revolucionaria concebida por Marx bajo el rótulo de "comunismo". Y es que el propio Marx, si bien escéptico ya hacia el uso ideologizado de la noción de fraternidad como mixtificación burguesa y nivelación aparentemente democratizante de propietarios y desposeídos, no puede por menos de ser tenido por uno de los mayores adalides con los que la causa histórica de la fraternidad haya contado jamás.

\section{El republicanismo de Marx y la crítica de la dominación}

El sentido histórico-conceptual de la fraternidad que hemos querido explorar en lo anterior llega a su madurez autoconsciente según Domènech en la I Internacional y su proyecto, abanderado en primera persona por Marx, de una "federación fraternal" de las clases trabajadoras de los distintos países con vistas a la republicanización de la vida colectiva (deposición del aparato estatal como excrecencia de la sociedad civil: esto es, la célebre y no siempre correctamente entendida "extinción del Estado" a la que tendremos ocasión de regresar) y del modo de producción (asociación entre libres e iguales para una apropiación común de las fuerzas productivas). Pues bien, antes de pasar revista a cómo se recoge esta tradición republicana de la democracia fraternal en los escritos históricos de Marx y a cómo impregna indirectamente, como a su través, la rigurosa analítica de las formas económicas que es El capital, hemos de situarnos en el punto crítico del itinerario marxiano en que por vez primera asoma la noción de una "verdadera democracia" en toda su radicalidad: el escrito del 43 en torno a la Crítica del derecho político de Hegel, sobre cuya ineludibilidad para la comprensión de lo que en Marx pueda haber de republicano nos ha llamado la atención con su acostumbrada maestría Miguel Abensour.

Vaya por delante una advertencia acerca de lo complejo y poco obvio del gesto teórico que supone un libro como La democracia contra el Estado: si Marx nos sigue interpelando hoy acuciantemente es por su sostenida voluntad de revelar lo inaceptable de una institución, el Estado, cuya finalidad sea, no tanto la de absorber y totalizar la multiformidad equívoca, conflictiva y plural del cuerpo social (el Estado racional de Hegel y su caricatura totalitaria), cuanto sobre todo, y ello es lo relevante hoy, la de obturar, aparentando dejar libre curso a las iniciativas y movimientos sociales y "representarlos" especularmente, la autopercepción por

dependencia personales" (Marx: 2007, 92); y, al respecto del despotismo autoritario fabril al que se ven sometido los trabajadores a pesar de las tendencias hacia la socialización del trabajo propias del modo de producción capitalista: "La conexión entre sus funciones, su unidad como cuerpo productivo global, radican fuera de ellos, en el capital, que los reúne y mantiene cohesionados. La conexión entre sus trabajos se les enfrenta idealmente como plan, prácticamente como autoridad del capitalista, como poder de una voluntad ajena que somete a su objetivo la actividad de ellos. Por consiguiente, si conforme a su contenido la dirección capitalista es dual porque lo es el proceso de producción mismo al que debe dirigir -de una parte proceso social de trabajo para la elaboración de un producto, de otra, proceso de valorización del capital-, con arreglo a su forma esa dirección es despótica” (Marx: 2010, 403). 
parte de la sociedad de su politicidad misma. Tal sería el "Estado democrático", clamoroso oxímoron para Abensour y, no en menor medida, para Marx. Como para Lefort y Rancière (y otros aún más egregios como Maquiavelo: no en vano reza el subtítulo de la obra, en guiño simultáneo a Lefort y Pocock, "Marx y el momento maquiaveliano", que se suma al de Clastres del título principal), el antagonismo y la división insuturables constituyen para Abensour el núcleo más íntimo de lo político, cuya verdad "insurgente", "salvaje", sería la apertura irreductible de lo social en la experiencia democrática radical, no clausurable ni encorsetable en el lecho de Procusto del tan confusamente esgrimido en nuestros días "Estado de Derecho". Abensour es sensible, no obstante, al peligro de maniqueísmo que entraña la dicotomía empleada con profusión por Castoriadis entre lo instituyente y lo instituido y no quiere ceder a lo que él, imputándoselo a Buber, denomina un "anarquismo «burdo»" (Abensour, 2017, 33), una mera inversión del esquema hegeliano en el que una sociedad espontánea y naturalmente "buena", una vez despojada del caparazón políticoestatal, se reconciliaría definitivamente consigo misma . Abensour, en la senda de Marx, busca todo lo contrario: repolitizar la sociedad ante la amenaza inminente, profetizada en su día por Carl Schmitt, de su neutralización consensual-gestionariamente consumada. Pero, contra Schmitt, tal estrategia no pasa por un robustecimiento catecóntico del Estado clásico hobbesiano, sino por la invención de espacios políticos no-estatales, por la revivificación del sujeto real de lo político: el dêmos, incategorizable en la tríada hegeliana de familia, sociedad civil y Estado, y como permeándola a toda ella transversalmente, que, en su pura irrupción y autodeterminación (eso sí, nunca coincidente consigo mismo, sino escindido, autocuestionándose permanentemente sin osificación ni identificación algunas que lo fijen), desborda los límites y horada la estructura de toda forma de dominación (mal llamada) política.

"Desorden fraternal", "no-dominación", "vínculo político no coercitivo" (Abensour, 2017, 40): tales son algunas de las precarias expresiones, por lo que de meramente negativas tienen (pero, ¿cómo tematizar positivamente lo no-dicho de la historia?), de las que Abensour se vale para dibujar esa difícil comunidad política ayuna de dominación y ajena a la forma-Estado. Y es que, efectivamente, en el Marx del 43 estaba en cuestión precisamente la posibilidad de inaugurar un discurso sobre lo político irreductible a formas filosóficopolíticas anteriores. Ello es lo que lo emparenta con Maquiavelo, y no tanto la tradición del humanismo cívico florentino escrutada por H. Baron y Pocock. También Maquiavelo quiso desestabilizar y subvertir el doble dispositivo que recorre toda la tradición de la filosofía política: por un lado, la delimitación y diferenciación escrupulosas del ámbito de la teoría con respecto al de la praxis que hagan subsumible esta en aquella, y, por otro lado, la concep-

4 No se trata, pues, aclara Abensour en el prólogo a la edición italiana ante las críticas suscitadas por su obra, de un anti-institucionalismo indiscriminado, sino de una institución de la libertad y de la no-dominación: "la democracia insurgente, lejos de ser por principio hostil a cualquier institución y a toda relación con el pasado, es selectiva. Llevada como cualquier movimiento político a inscribirse en el tiempo, distingue entre las instituciones que favorecen la acción política del pueblo y las que no la favorecen. El criterio para su decisión es la no-dominación. No hay antagonismo sistemático entre la democracia insurgente y las instituciones, siempre y cuando estas trabajen por conservar ese estado de no-dominación y actúen como diques de contención del deseo de dominar de los grandes, y hagan posible, haciéndolo, las experiencias de libertad del pueblo" (Abensour, $2017,42)$. 
ción de la política necesariamente como dominación de...sobre... que ponga fin al tumulto originario en el que, por el contrario, consiste más bien el vivere civile para Maquiavelo.

En el anti-teoreticismo (que no irracionalismo, evidentemente, sino justamente de una racionalidad filosófica inusitadamente penetrante, fuera de lo común) de Marx no conviene aquí detenerse demasiado, aunque no quiero dejar de notar que, atravesando como atraviesa la totalidad de la obra marxiana, está también presente en el manuscrito del 43, donde resuena irónicamente el retruécano, esa figura retórica tan cara a Marx para poner de manifiesto las inconsistencias de aquello que combate, de que en la filosofía hegeliana del derecho lo que verdaderamente impera "no es la lógica de la cosa [esto es, del Derecho y del Estado], sino la cosa de la lógica" (Marx, 1982, 331), de que la racionalidad, la sustancialidad, la subjetividad, etc., del Estado en Hegel no son más que aplicaciones ad hoc del grandioso aparato conceptual desplegado en la Ciencia de la lógica, pero que igualmente pueden servir para dar cuenta de cualesquiera fenómenos por muy dispares que sean (la revolución de los planetas, la fotosíntesis o la tragedia griega, por ejemplo). Pero como siempre, Marx no se enmaraña aquí en una disquisición puramente epistemológica al desenmascarar que "Hegel, en vez de concebirlos [los predicados] como predicados de sus sujetos, sustantiva los predicados y luego, mediante una operación mística, los convierte $a$ posteriori en sus sujetos" (Marx, 1982, 336): si denuncia el carácter abstracto de los conceptos fundamentales de la teoría política de Hegel es porque de él se derivan posiciones "prácticas" (en puridad, no serían tales, pues la praxis en Marx no se deja pautar por teoría alguna) radicalmente incompatibles con la autodeterminación real del pueblo de la que dimanaría la "verdadera democracia". Caso paradigmático sería sin lugar a dudas el de la soberanía estatal: si prescindimos de su sujeto real, todos los hombres de carne y hueso que de facto detentan el poder (mas no en el sentido del contractualismo, ni rousseauniano ni hobbesiano: el individuo es siempre ya social, no ingresa en la socialidad desde una renuncia a su supuesta potestad "natural" radicalmente individual; aquí nos movemos más bien, tal vez, tras la pista de La Boétie: el tous Un soberano no es tal sino por la segmentación idiotizante de los tous uns), y partimos de su esencia objetivada e independiente de él (la soberanía), podremos luego resubjetivizarla y como incorporarla, encarnarla en la figura de un sujeto determinado que pasaría a diferenciarse de todos los demás. Este, huelga decirlo, no tiene por qué ser siempre uno físicamente, como bien diagnóstico Lefort en su crítica del totalitarismo como incorporación imaginaria, pero sí en el caso del monarca constitucional hegeliano que Marx tiene aquí en mente.

Marx asiente únicamente a la premisa menor del silogismo político hegeliano, que podríamos desgranar de la siguiente manera: 1) existen la personalidad y la subjetividad (entiéndase: del Estado); 2) personalidad y subjetividad sólo pueden ser predicados de la persona del sujeto; ergo, 3) la persona es Uno, es realización concreta de la esencia una de la personalidad y de la subjetividad, y una será la persona que encarne la soberanía (la personalidad y subjetividad del Estado). Con ello, protesta Marx, Hegel nos introduce de contrabando una ontología totalizante y unitaria que imposibilita de todo punto la ontología plural democrática. Por el contrario, “debiera proseguir Hegel, lo Uno sólo tiene verdad pura y simplemente como muchos unos. El predicado, la esencia, jamás agota las esferas de su existencia en un Uno, sino en muchos Unos" (Marx, 1982, 340). El sujeto real concreto existente es siempre ya sujeto-con, excéntrico, incapaz de reunir en sí mismo sin resto toda 
su propia sustancialidad. Y a un sujeto tal a Marx no le duelen prendas en atribuirle el nombre de pueblo: comunidad tan "metafísicamente" imposible como "políticamente" necesaria, diseminada en la serie imprevisible e iterable in infinitum de los "muchos Unos" a la que no cabe oponer ni cabe subsumir en ninguna "soberanía".

En una intuición fulgurante, Marx le reconoce a Hegel que, en efecto, "si la soberanía existe en el monarca, resulta una necedad hablar de una soberanía antagónica en el pueblo, ya que el concepto de soberanía excluye la posibilidad de una existencia doble [léase: plural] y, más aún, antagónica" (Marx, 1982, 341-342; cursiva nuestra). Así pues, aunque el propio Marx no lo formule así, seducido como estaba por la potencia semántica de la consigna revolucionaria de la "soberanía popular", nos topamos con una disyunción excluyente: o democracia o soberanía (Estado), tertium non datur. Dado que lo político consiste en el antagonismo íntimo e igualitario del pueblo consigo mismo, todo intento por bloquearlo subordinando alguno de sus elementos al orden formalmente político del Estado (la Constitución) es, por ello mismo, despolitizante: aniquila la dimensión propiamente constituyente del dêmos en aras de su esquematización constitucional pasiva. Contra el "pueblo" de la Constitución (equivalente, sin demasiadas fricciones, a la sociedad civil burguesa, "impolítica" en sí misma y sólo pseudopolitizada mediatamente a través del trampantojo de la "representación"), por tanto, la constitución del pueblo. Es en ese sentido en el que Marx tilda a la democracia de "enigma resuelto de todas las constituciones" (Marx, 1982,343): en ella, el principio formal de las mismas (la orientación hacia el "interés general" determinada por unas directrices que la multitud, cuyo interés se trata precisamente de favorecer, ha recibido externamente del poder racional del Estado) deviene principio material: la multitud se dota a sí misma de ese poder y anula la distinción abstracta e ideológica entre bourgeois y citoyen. Ello implica que el Estado se revele, no como instancia de lo universal, sino como "contenido particular", como puro aparato administrativo, podríamos decir, para la subvención de las necesidades organizativas del dêmos, perdiendo de tal manera su carácter propiamente político, el cual vendría a desplazarse hacia la autodeterminación misma, siempre lábil e imprevisible, del pueblo.

He aquí un párrafo de pasmosa actualidad, casi dos siglos después, cuando imperan y proliferan regímenes democráticos (sedicentes "Repúblicas" algunos de ellos, para más inri) más o menos homologados por todo el orbe:

En todos los Estados distintos de la democracia, el Estado, la ley, la Constitución son lo dominante, sin que realmente dominen, es decir, sin que penetren de un modo material el contenido de las demás esferas no políticas. En la democracia, la constitución, la ley, el Estado mismos son solamente la autodeterminación del pueblo y el contenido material de éste, en cuanto es constitución política (Marx, 1982, 344).

El Estado político ha de dejar de pretender ser, por tanto, la racionalización formal (condensada por antonomasia en el aparato burocrático) del por sí mismo caótico y sumido en el bellum omnium contra omnes Estado "material", empírico. Ha de manifestarse por fin como la "ilusión política de la sociedad civil" (Marx, 1982, 374), pues en el fondo ni el soberano, ni el funcionario, etc., son otra cosa que personas privadas autorizadas y legitimadas a llevar la gerencia de los asuntos "generales" por el orden constitucional positivo, dentro del cual ha de enmarcarse necesariamente toda acción del poder legislativo, y que, en consecuencia, se 
pliegan a la lógica no-política de la dominación y a su desactivación de la potencia política de lo social. Pero, y esta es la gran artimaña del Estado hegeliano (que no es para Marx sino la más lograda descripción y teodicea filosófica del Estado moderno tout court), lo que se pasa por alto presuponiendo la validez a priori del orden constitucional es que, a su vez, "la constitución se hallaría hors de loi si se hallara fuera del poder legislativo" (Marx, 1982, 367), si se hurtase a la insistente (an-árquica, como veremos) exigencia democrática por parte del pueblo de estar en condiciones de implicarse y formar parte activa de su propia constitución política.

De lo dicho hasta aquí se colige con meridiana claridad que Marx se alinea expresamente en la tradición democrático-popular que Domènech nos ha ayudado a desempolvar del archivo oculto de la historia. Es por ello que no debe sorprender que el texto del 43 conduzca en línea recta, pasando por la crítica de la recomposición burguesa tras (y a través de, como se interpreta con clarividencia en El 18 Brumario) las embestidas de 1830 y 1848, al elogio entusiasta y sincero de la Comuna de París. En ella leyó Marx la nunca antes acometida tentativa de subvertir los fundamentos mismos del Estado como forma de dominación y de apuntar directamente, sin enredarse en los mecanismos ideológicos de la representación que paralizan las tendencias revolucionarias inherentes al sufragio universal, a su "carácter de poder nacional del capital sobre el trabajo, de fuerza pública organizada para la esclavización social y de máquina del despotismo de clase" (Marx, 2014, 32). Una toma de poder animada por un tal espíritu republicano (recordemos: lo que Marx propugna es una politización de la sociedad) dista mucho de poder ser reducida a mero "golpe de Estado", a mera substitución de una forma de dominación por otra; de ahí la reivindicación por parte de los proletarios insurrectos de una "república social", no meramente "política" (en el sentido degradado de la expresión que, como hemos visto, se deja traducir por "formal" o "estatal"), la cual en realidad "no expresaba más que el vago anhelo de una república que no acabase sólo con la forma monárquica de la dominación de clase, sino con la propia dominación de clase. La Comuna era la forma positiva de esta república" (Marx, 2014, 35).

El pueblo en armas contra el ejército permanente y el cuerpo policial ajenos e independizados de la propia sociedad civil al servicio del statu quo; funcionarios electos por sufragio universal, responsables y revocables en todo momento, contra la sumisión del funcionariado al poder del Estado que le había alumbrado y que le había otorgado un cargo al que se aferraba con rígida obstinación, ... Podrían añadirse innumerables innovaciones estrictamente institucionales que la Comuna haya aportado (enseñanza gratuita y libre de injerencias ideológicas, por citar un último e importantísimo ejemplo), pero el denominador común de todas ellas era sin duda la comunalización, la descentralización política e institucional de la nación, la cual, lejos de implicar su desmembración (de hecho, en ningún momento se puso sobre la mesa la abolición del "Gobierno" central, por mucho que, eso sí, se decretase su exención de todo poder soberano), como argüían aviesamente los adversarios del pueblo, contribuía a su propia formación como tal:

No se trataba de destruir la unidad de la nación sino, por el contrario, de organizarla mediante un régimen comunal, convirtiéndola en una realidad al destruir el poder del Estado, que pretendía ser la encarnación de aquella unidad independiente y situada por encima de la nación misma, en cuyo cuerpo no era más que una excrecencia parasitaria (Marx, 2014, 37). 
Excrecencia parasitaria que no hacía sino perpetuar la esclavitud social de los productores bajo la fachada de su emancipación sedicentemente política. Es por ello que la realización verdaderamente política de la nación conduce inexorablemente, a través de la despolitización del Estado y la repolitización de la sociedad, a la erradicación de la propiedad privada de los medios de producción (que es la que posibilita la dependencia y la dominación en el régimen de igualdad jurídica del trabajo "libre" asalariado) y a la asociación "republicana" de productores libres e iguales.

Si secundamos la propuesta hermenéutica de Nicos Poulantzas, habrá que reconocer que también en el propio Capital, a despecho de ser una descripción científica de la matriz del modo de producción capitalista y un análisis explícito de su nivel económico, "las otras instancias -lo político, lo ideológico- están muy presentes [...], pero en cierto modo en hueco, por sus efectos en la región económica" (Poulantzas, 2007, 14). Es más, nos atreveríamos a aventurar, en El capital hay también "en hueco", no sólo una teoría del Estado capitalista, sino un desfondamiento crítico de toda posible noción autónoma y separada de Estado que no sería sino la impronta republicana que desde su temprano enfrentamiento con Hegel modula y orienta todo su pensamiento. De El capital se desprende con suficiente evidencia que el Estado, en su autonomía específica con respecto a las demás instancias del modo de producción capitalista, desempeña el papel decisivo de contener dentro de un marco institucional y jurídico soportable el conflicto de clases (en realidad mediante una premeditada y calculada no-intervención que se limita a fijar y a dotar de vigor a un "sistema" de derecho que regula la totalidad de las relaciones sociales vertebrándola sobre ciertas nociones fundamentales: sujeto, propiedad, contrato, intercambio, etc.), erigiéndose así en el factor más relevante de la cohesión social, en sutil conjunción con sus aspectos técnico y específicamente ideológico. Cabría declinar de otro modo, por lo demás, la percepción de lo que hay de político en El capital transmitida por Poulantzas: lo político no es propiamente el modo en que el Estado mantiene latente el conflicto; como hemos insinuado ya en la estela agonista de Rancière y Lefort (quienes, dicho sea de paso, interpretaron a nuestro modo de ver erróneamente la concepción marxiana de la "sociedad sin clases" como un ideal más de sociedad reconciliada consigo misma, autotransparente y "metapolítica", sin reparar en la veta republicana en la obra marxiana que estamos intentando desenterrar y que habría que restituirle de una vez), lo político no es sino el conflicto, el disenso mismo: condición de posibilidad de la emergencia de toda novedad histórica, de toda apertura de lo social.

El Estado capitalista conseguiría más bien suspender lo político mediante un peculiar efecto de aislamiento operado por un armazón jurídico-ideológico centrado en la categoría de "individuo desnudo" que Marx acertó a identificar en los Grundrisse como presupuesto conceptual e histórico de la formación social capitalista (categoría que ha de retrotraerse al carácter formal y abstracto del derecho privado romano, verdadera matriz histórica, a través de sus fluctuantes evoluciones medievales y de su conmixtión con el derecho canónico en lo que se dio en llamar el ius commune, del derecho moderno). Tal efecto consistiría en que "las estructuras jurídicas e ideológicas -...- instauran, en su nivel, a los agentes de la producción distribuidos en las clases sociales en «sujetos» jurídicos y económicos, y tiene como efecto, sobre la lucha económica de clases, ocultar, de manera particular, a los agentes sus relaciones como relación de clase" (Poulantzas, 2007, 159). La compraventa de fuerza de trabajo, piedra angular en la arquitectónica del capital y verdadera differentia specifica que este trajo consigo, 
se caracteriza eminentemente por el hecho de que quien la vende es propietario de ella, no se enajena sí mismo completamente en el contrato laboral a la manera del esclavo, sino que la pone a disposición de su comprador transitoriamente para que este, durante ese ínterin, haga un uso temporal de ella en la producción de otras mercancías que encarnen un valor de cambio mayor que aquel por el cual se apropió de la fuerza de trabajo. Pero, como dictamina un locus classicus marxiano, "él y el poseedor de dinero se encuentran en el mercado y traban relaciones mutuas en calidad de poseedores de mercancías dotados de los mismos derechos, y que sólo se distinguen por ser el uno vendedor y el otro comprador; ambos, pues, son personas jurídicamente iguales" (Marx, 1984, 204). Por qué uno aparezca como poseedor de esa extraña mercancía que es su propio tiempo de vida y el otro como poseedor de dinero es un factum brutum que, como tal, carece de toda inteligibilidad o razón de ser ulterior (siempre y cuando no historicemos esa relación, que es justo lo que se propuso Marx).

La perversión de la dominación capitalista reside, pues, en lo que podemos llamar la consumación de su carácter ideológico mediante su desideologización material: se presenta en cierta medida como inexistente, estando como están dominante y dominado nivelados en el plano jurídico (y, ¿qué es la perversión sino una relación puramente negativa e imaginaria con la Ley que torna esta aún más férrea y constrictiva?). No hay factores, ya sean de índole natural (el esclavo era mero instrumentum vocale "por naturaleza"), ya de índole estamental ( siervos de la gleba), que pudieran justificar una asimetría entre ambos. En cambio, como es sabido, la dependencia y la dominación en las formaciones sociales precapitalistas eran inmediatas y explícitas, socialmente identificables, jurídico-políticamente sancionadas y, por añadidura, revestidas de una cobertura ideológica (religiosa, fundamentalmente) que las legitimaba. En condiciones capitalistas, como hemos apuntado, la dominación y la dependencia no son menos inmediatas: el capital, trabajo muerto acumulado, domina el trabajo vivo de manera directa, pero tal dominación tiene lugar extrajurídicamente y fuera de todo desdoblamiento ideológico. ¿Cómo ocurre ello? El jurista marxista E. Pašukanis nos legó al respecto algún un atisbo iluminador: el Estado no es simplemente el "aparato de la clase dominante"; es una "fuerza impersonal" que

no media cada relación de explotación, puesto que el asalariado no está obligado política y jurídicamente a trabajar para un patrón determinado, sino que vende formalmente su fuerza de trabajo por medio de un libre contrato. [...] Las relaciones de dominación y de servidumbre pueden así existir igualmente en el modo capitalista de producción, sin separarse, por tanto, de la forma concreta bajo la cual aparecen: como dominación de las relaciones de producción sobre los productores. Pero dado que precisamente no aparecen aquí bajo una forma enmascarada [...] pasan inadvertidas a los ojos de los juristas" (Pašukanis, 1976, 120-121).

Como en La carta robada de Poe, la dominación capitalista se hace inexpugnable de puro clamorosa y evidente, mientras que el poder del Estado idealmente no implica sino una coacción abstracta, general, objetiva e imparcial que protege a todos los miembros suyos que entren en relaciones jurídicas entre sí. Escrita hace casi un siglo, la obra de Pašukanis, pese a lo tosco en ocasiones de su lenguaje, no ha perdido un ápice de su vigencia, y creo que todos podremos reconocer en ella algo de lo difuso, volátil y obsceno de la gobernanza neoliberal. 
Mucho más recientemente, y centrándose no tanto en la forma jurídica cuanto en las nociones basilares de valor y capital, Moishe Postone ha propuesto que el carácter "abstracto" de la dominación capitalista se debe a que la independencia jurídica de las personas distorsiona el hecho de que el tiempo de vida que se entrega a la producción se homogeneiza y se descualifica, pues la propia dinámica del valor (histórica, recordemos, no natural y eterna, como quisieron los economistas liberales y algunos marxistas) succiona, para reproducirse y revalorizarse, cada vez más tiempo abstracto (trabajo "social", el vivo y el muerto, que no es el de este o aquel trabajador presionado por este o aquel capitalista, y que es la fuente última del valor y del plusvalor, por muy velada que esté por la pseudo-equivalencia salarial), constituyendo una forma de dominación que

no puede ser suficientemente aprehendida en tanto dominación y control de la mayoría de las personas y de su trabajo por unos pocos. En el capitalismo, el trabajo social no es sólo objeto de dominación y explotación sino que es, en sí mismo, el territorio esencial de la dominación. El modo impersonal, abstracto y «objetivo» de dominación característico del capitalismo está en relación intrínseca con la dominación de los individuos por su trabajo social (Postone, 2006, 186).

El paso de El capital en que esto se tematiza de una manera más explícita es sin duda el capítulo, de tan prolongada y sostenida Wirkungsgechichte (Lukács, Sohn-Rethel, Borkenau,..., casi cabría decir que hasta Žižek y su sagaz relectura lacaniana de la ideología), sobre el fetichismo de la mercancía, el cual no consistiría sino en una objetivación ontologizante de lo que son relaciones sociales históricamente determinadas. Lo que aquí nos interesa es que, en una formación social estructurada exclusivamente en torno al y a través del intercambio de mercancías (y tal fue "la gran transformación" de que nos habló Polanyi), el trabajo abstracto, independiente por completo del producto al que haya podido dar lugar (o, lo que viene a ser lo mismo, la abstracción uniformizante del tiempo de la vida de los individuos: verdadera "sustancia" del valor), deviene la forma privilegiada de mediación social, de relación con el otro: esta se reduce, por ende, a la adquisición de algunos de sus bienes para mi uso como contrapartida de una parte del valor de cambio que a mí me granjea la venta de mi fuerza de trabajo. Pues, evidentemente, la sociedad capitalista no está compuesta de robots ni de ángeles, y en última instancia el producto ha de ser consumido: valor de uso y valor de cambio, no obstante, son dos caras de la misma moneda, la forma-valor; y esa mercancía tan peculiar y enigmática que es la fuerza de trabajo, para ser consumida, abandona ese "Edén de derechos humanos innatos" que es la esfera de la circulación y en el que imperan "la libertad, la igualdad, la propiedad y Bentham", e ingresa en "la oculta sede de la producción" (Marx, 1984, 214). Es en la esfera de la producción donde propiamente se valoriza el valor y se reproduce el capital a escala ampliada, imprimiéndole a la totalidad social una dinámica y una dirección (generando tiempo histórico, aun a su pesar ${ }^{5}$ ) de autovalorización incesantes que entra en conflicto con el carácter puramente abstracto y monótono del tiempo del que dicha dinámica se alimenta para subsistir.

5 "La dialéctica, en la que cada nuevo nivel de productividad es redeterminado como nivel básico del marco temporal abstracto de referencia que funciona como una norma coaccionadora socialmente general, puede ser conceptualizada como un proceso por el cual el carácter social del trabajo, en tanto actividad productiva, se convierte estructuralmente en un atributo de la totalidad, totalidad que, aunque esté constituida por la práctica 
A la manera de la cura analítica, sólo es posible aprehender la historicidad de la formación social capitalista (y, en consecuencia, desprenderse de ella como destino) al reparar, como nos indica Postone, en su dualidad constitutiva y autodestructiva, mas no en el sentido un tanto obtuso y determinista de Rosa Luxemburg y Henryk Grossmann, sino en uno secretamente emparentado con la ambivalencia freudiana: "El capital es la forma alienada de ambas dimensiones [abstracta como valor y concreta por su carácter social] del trabajo social en el capitalismo, enfrentada a los individuos como Otro totalizador y extraño" (Postone, 2006, 449). Sólo desde la perspectiva de la crítica y de la historicidad podremos caer en la cuenta de que toda totalización es fallida (e intrínsecamente injusta), de que el crimen, por decirlo con Jorge Alemán, nunca es perfecto: toda formación social estará transida de dominación única y exclusivamente mientras la propiedad y Bentham no sean sustituidos en el Edén de la circulación por la fraternidad preterida. De que ello siempre será posible, aunque sólo sea utópicamente posible, nos ha dejado constancia la "extravagante hipótesis" de Emmanuel Levinas.

\section{La "extravagante hipótesis" de un republicanismo anárquico}

Han de tomarse las apresuradas líneas que siguen más bien como un bosquejo que incite a una ulterior investigación, en modo alguno como consideraciones conclusivas. Una interrogación será la última palabra: ¿cabe reducir la torsión marxiana de lo político a la tradición del republicanismo canónico cuyo marco histórico nos ofrece Domènech? Nuestra sospecha es que en cierto modo lo excede, que la fraternidad que se transparenta en Marx remite a una de las fuentes que la tradición política ha cegado deliberadamente por lo que de desestabilizador para su autorreferencialidad concéntrica en ella pudiera esconderse: la revelación bíblica. Desde luego, la tesis no es novedosa. Benjamin, Bloch, J. P. Miranda, Dussel, entre otros muchos, la han ensayado con diversa fortuna. Por otra parte, contradice la sólida argumentación histórica de Domènech, quien, haciéndose eco de las increpaciones maquiavelianas a la Iglesia, realiza en De la ética a la política una impenitente crítica del "apoliticismo" paulino como germen de una funesta domesticación de las poblaciones que las hará dóciles y pusilánimes. No es este el lugar de revisarla, pero desde luego la literatura reciente sobre el tema (Taubes, Badiou, Agamben, Žižek,...; por nuestras latitudes, J. L. Villacañas) daría pie a la discusión.

En cualquier caso, no pretendo ni mucho menos con estas someras indicaciones, lo cual por fuerza habría de ser deshonesto, "judaizar” a Marx, condición de la que él renegó expresamente, sino captar las resonancias vivas, metamorfoseadas por ese proceso cultural aún no bien entendido que fue la asimilación, de una "tradición oculta" que piensa el saber, lo político y, en general, la (in)condición humana de otro modo. Abensour extracta de la obra de Levinas, tal vez la más sólida traducción a lenguaje filosófico de la tradición del

social, se opone y domina a los individuos. En este sentido la dimensión abstracta del trabajo se «apropia», por así decirlo, de la dimensión concreta" (Postone, 2006, 449). La autocontradictoriedad del capital no es de orden, pues, ni lógico ni ontológico, no nos garantiza su necesario "derrumbe": consiste en que desata, con su tendencia hacia la autovalorización incesante, una dinámica histórica por su misma naturaleza contraria a la dominación abstracta. Que ésta siga estando guiada por el "sujeto automático" sólo depende de que este siga siendo capaz de absorber abstractivamente el trabajo concreto de los individuos vivientes. Pero no es a priori vaticinable ni que lo siga siendo ni que no. 
profetismo ético judío con la que contamos, algo así como una "extravagante hipótesis": lo político como limitación, no de la violencia, sino de la responsabilidad hiperbólica para con el otro mediada por la llegada del tercero que introduce la medida y la justicia (no abstractas, sino dirigidas a una singularidad intransferible, pues seguimos estando ante un otro del otro: imposible no evocar aquí la Crítica del programa de Gotha); lo político como "el tiempo del paso de la disimetría de la relación ética a la reversibilidad entre ciudadanos" (Abensour, 2007, 302), reversibilidad siempre tensionada por lo anárquico y u-tópico, por lo irreducible a principio, de la relación ética, de la proximidad: relativización de lo político que es más su fisura y sobredeterminación internas que esa reducción a una instancia ajena (la "ética") que buscan ciertas lecturas ideologizantes de Levinas. En los intersticios de lo político se abre una exigencia infinita: la de un "más allá del Estado en el Estado", como Levinas intituló una de sus lecturas talmúdicas. En él ha de seguir reverberando, por muy tenuemente que sea, el emplazamiento que, contra todos los presupuestos de la "antropología" liberal, el otro me hace antes de todo consentimiento o compromiso por mi parte, "antes de cualquier relación contratada" (Levinas, $2003,148)$. Es en este sentido dia-crónico, irrecuperable e intematizable por el saber, que la inyunción bíblica de amar al prójimo lo convierte, "de golpe", en mi hermano, más allá de toda biología, de todo parentesco y de todo melifluo humanitarismo, y desbaratando la lógica irrefrenable del conatus individualista posesivo:

Aquí la fraternidad precede a la comunidad del género. Mi relación con el otro en tanto que prójimo confiere sentido a mis relaciones con todos los otros. Todas las relaciones humanas, en tanto que humanas, proceden del desinterés. [...] Ello quiere decir de modo concreto y empírico que la justicia no es una legalidad que rige las masas humanas, de la cual se saca una técnica de «equilibrio social» poniendo en armonía fuerzas antagónicas, lo cual sería una justificación del Estado dejado a sus propias necesidades. [...] La justicia, la sociedad, el Estado y sus instituciones -los intercambios y el trabajo comprendido a partir de la proximidad-; todo ello significa que nada se escapa al control propio de la responsabilidad del uno para con el otro. Es importante encontrar todas estas formas a partir de la proximidad, en la cual el ser, la totalidad, el Estado, la política, las técnicas o el trabajo están en todo momento a punto de encontrar su centro de gravitación en ellos mismos, de juzgar por su propia cuenta (Levinas, 2003, 239).

Cabría leer, para concluir, este texto como una suerte de "manifiesto" republicano que invierte por completo las coordenadas metafísicas, psíquicas, morales, jurídicas y económicas desde las que pensamos la política y nuestra vida en común al menos en dos sentidos: rebatiendo que la praxis tenga un "principio" (el "saber", el "interés", ...) y revelando su (in)condición an-árquica, sólo sostenida por la "proximidad" del prójimo y la justicia intematizable que brota de la coordinación horizontal de los distintos "otros". Pero, ciertamente, se trata de un republicanismo aún por venir, cuyo barrunto en la obra marxiana, que aquí hemos intentado desplegar, tal vez sea uno de los acicates que nos sigan exhortando a beber de ella para enfrentarnos a nuestro incierto futuro. 


\section{Obras citadas}

Abensour, Miguel (2007): Para una filosofía política crítica, Anthropos, Barcelona.

Abensour, Miguel (2017): La democracia contra el Estado. Marx y el momento maquiaveliano, Catarata, Madrid.

Domènech, Antoni (2004): El eclipse de la fraternidad. Una revisión republicana de la tradición socialista, Crítica, Barcelona.

Levinas, Emmanuel (2003): De otro modo que ser o más allá de la esencia, Sígueme, Salamanca.

Marx, Karl (1982): "Crítica del Derecho del Estado de Hegel", en Escritos de juventud, FCE, México D.F.

Marx, Karl (1984): El capital. Crítica de la economía política, Libro I, Vol. 1, Siglo XXI, Madrid.

Marx, Karl (2007): Elementos fundamentales para la crítica de la economía política (Grundrisse), vol.1, Siglo XXI, México D.F.

Marx, Karl (2010): El capital. Crítica de la economía política, Libro I, Vol. 2, Siglo XXI, Madrid.

Marx, Karl (2014): “Manifiesto del Consejo General de la Asociación Internacional de Trabajadores sobre la guerra civil en Francia en 1971", en Marx, Karl; Engels, Friedrich; Lenin, Vladimir Illich (2014): La Comuna de París, Akal, Madrid.

Pašukanis, Evgeni (1976): Teoría general del derecho y marxismo, Labor, Barcelona.

Postone, Moishe, (2006): Tiempo, trabajo y dominación social, Marcial Pons, Madrid.

Poulantzas, Nicos (2007): Poder político y clases sociales en el Estado capitalista, México D.F., Siglo XXI. 
